\title{
Inhibition of proteasome by bortezomib causes intracellular aggregation of hepatic serpins and increases the latent circulating form of antithrombin
}

\author{
David Hernández-Espinosa ${ }^{1}$, Antonia Miñano ${ }^{1}$, Constantino Martínez ${ }^{1}$, Adriana Ordoñez ${ }^{1}$, Elena Pérez-Ceballos ${ }^{1}$, \\ Felipe de Arriba ${ }^{1}$, Rubén A Mota ${ }^{2}$, Francisca Ferrer ${ }^{1}$, Marcos González ${ }^{3}$, Vicente Vicente ${ }^{1}$ and Javier Corral ${ }^{1}$
}

Conformational diseases include heterogeneous disorders sharing a similar pathological mechanism, leading to intracellular aggregation of proteins with toxic effects. Serpins are commonly involved in these diseases. These are structurally sensitive molecules that modify their folding under even minor genetic or environmental variations. Indeed, under normal conditions, the rate of misfolding of serpins is high and unfolded serpins must be degraded by the proteasome system. Our aim was to study the effects of bortezomib, a proteasome inhibitor, on conformationally sensitive serpins. The effects of bortezomib were analysed in patients with multiple myeloma, HepG2 cells, and Swiss mice, as well as in vitro. Levels, anti-FXa activity, heparin affinity, and conformational features of antithrombin, a relevant anticoagulant serpin, were analysed. Histological, ultrastructural features and immunohistological distribution of antithrombin and $\alpha 1$-antitrypsin (another hepatic serpin) were evaluated. We also studied the intracellular accumulation of conformationally sensitive (fibrinogen) or non-sensitive (prothrombin) hepatic proteins. The inhibition of the proteasome caused intracellular accumulation and aggregation of serpins within the endoplasmic reticulum that was associated with confronting cisternae and Mallory body formation. These effects were accompanied by a heat stress response. Bortezomib also increased the levels of intracellular fibrinogen, but has no significant effect on prothrombin. Finally, bortezomib had only minor effects on the mature circulating antithrombin, with increased amounts of latent antithrombin in plasma. These results suggest that the impairment of proteasomal activities leads to an intracellular accumulation of conformationally sensitive proteins and might facilitate the release of misfolded serpins into circulation where they adopt more stable conformations.

Laboratory Investigation (2008) 88, 306-317; doi:10.1038/labinvest.3700717; published online 14 January 2008

KEYWORDS: proteasome inhibitors; bortezomib; serpin; heat-shock proteins; conformation; aggregation

Serpins are relevant inhibitors of serine proteases in multiple physiological systems that have a tightly conserved and wellcharacterised structure. The key to their function and to their evolutionary success is their unique and efficient mechanism of inhibition of the target proteases, which requires a highly flexible structure. However, this conformational flexibility also renders serpins particularly susceptible to even minor modifications, such as point mutations or environmental agents, which might trigger the formation of abnormal conformers. ${ }^{1}$ The conformational instability of serpins confers a disadvantage over and beyond the loss of activity. Thus, abnormal conformers of serpins might form toxic intracellular aggregates that contribute to certain conformational diseases. ${ }^{2}$

The ubiquitin-proteasome system has been characterised as the most important cell machinery to degrade misfolded secretory proteins. ${ }^{3}$ As expected for structurally sensitive molecules, this machinery has been shown to be extremely important for intracellular degradation of abnormal conformers, proper folding and release of serpins, such as antithrombin, ${ }^{4-6} \alpha 1$-antitrypsin, ${ }^{7,8}$ and neuroserpin. ${ }^{9}$ Impairment of this system has been one of the main contributing factors to a number of conformational diseases, mainly neurological disorders. ${ }^{10}$ However, the inhibition of

\footnotetext{
${ }^{1}$ Department of Medicine, Centro Regional de Hemodonación, Murcia, Spain; ${ }^{2}$ Department of Biochemistry, Molecular Biology B and Immunology, University of Murcia, Murcia, Spain and ${ }^{3}$ Hematology Service, Hospital Clínico Universitario, Salamanca, Spain

Correspondence: Dr J Corral, PhD, Centro regional de Hemodonación, Ronda de Garay s/n. 30003 Murcia, Spain. E-mail: javier.corral@carm.es

Received 3 October 2007; accepted 4 November 2007
} 
proteasome has also been exploited for the fight against cancer. Indeed, bortezomib is a promising treatment in multiple myeloma (MM), prostate and lung cancer. ${ }^{11}$ Unfortunately, no studies have been carried out to unveil the effects of bortezomib treatment on conformationally sensitive serpins in patients or mice models. Therefore, the aim of our study was to investigate the consequences of bortezomib treatment on serpins.

\section{MATERIALS AND METHODS In Vitro Studies}

Venous blood from healthy blood donors $(n=4)$ was anticoagulated with $11.3 \mathrm{mM}$ trisodium citrate. Fresh plasma from these samples was obtained by centrifugation and immediately stored in aliquots at $-70^{\circ} \mathrm{C}$. Plasma samples were incubated with a wide range of concentrations of bortezomib $(1-100 \mu \mathrm{M})$ for $24 \mathrm{~h}$. Similar studies were performed with purified human antithrombin obtained from commercial concentrates of therapeutic use (Kybernin-P, Zbl-Behring, Strasbourg, France).

\section{Patients}

MM patients $(n=7)$, received i.v. bortezomib following the schedule used in the SUMMIT protocol Velcade $^{\text {TM }}$, Janssen-Cilag Ltd, Saunderton, UK). Briefly, $1.3 \mathrm{mg} / \mathrm{m}^{2}$ of bortezomib were i.v. administered to patients on days $0,4,8$, and 11 of every block of therapy (21 days) for an average of six blocks of therapy (18 weeks). Venous blood from MM patients under bortezomib treatment was collected into $0.102 \mathrm{M}$ trisodium citrate tubes $(3.2 \%)$ on days $0,1,4$, and 8 of the first block of chemotherapy. Fresh plasma from these samples was obtained by centrifugation and immediately stored in aliquots at $-70^{\circ} \mathrm{C}$ until the moment of use.

Additionally, we analysed the $\alpha 1$-antitrypsin genotype and retrieved clinical data retrospectively from 34 patients with MM treated with bortezomib.

The Local Ethics Committee approved the protocol, and informed consent was obtained from patients or their relatives.

\section{Cell Culture Studies}

Semi-confluent cultures of the human hepatoma HepG2 cell line cultured in Dulbecco's modified Eagle's medium (GibcoBRL, Paisley, UK) $+10 \%$ fetal calf serum (FCS, GibcoBRL, UK) were extensively washed with PBS, and incubated in FCS-deprived Dulbecco's modified Eagle's medium (GibcoBRL, UK) and treated with either 10 or $50 \mu \mathrm{M}$ bortezomib $(n=8)$. Control cells were incubated using the same volumes of sterile PBS. Cell culture medium samples from these groups were collected $(250 \mu \mathrm{l})$ at $24 \mathrm{~h}$ post-treatment and frozen at $-70^{\circ} \mathrm{C}$ until the moment of use. Cells were either fixed in 4\% PBS-formaldehyde or lysated for immunofluorescence or immunoblotting studies.

\section{Mouse Model}

Non-inbred Swiss (ICR CD-1 $\left.{ }^{\mathrm{TM}}\right)$ male mice $(n=18)$ were i.p. injected with $1.3 \mathrm{mg} / \mathrm{m}^{2}$ bortezomib on days 0 and +4 following the dose and scheme used in humans. Moreover, we also injected the drug on day +5 to evaluate the effects of cumulative dosing. Controls were i.p. injected with the same volume $(100 \mu \mathrm{l})$ of sterile $0.9 \%$ saline following the same dosage regime $(n=6)$. Venous blood samples $(20 \mu \mathrm{l})$ were carefully collected on days $0,+1,+5$, and +6 posttreatment into $10 \mathrm{mM}$ trisodium citrate-containing tubes. Bortezomib-treated mice were killed on days $+1(n=6)$, $+5(n=6)$, and $+6(n=6)$, respectively, and all control mice were killed at the end of the experiment. After killing, livers were finely dissected and either fixed in 4\% PBSformaldehyde for histopathology purposes, or in $4 \%$ glutaraldehyde for electron microscopy purposes, or frozen into liquid nitrogen for immunoblotting purposes. The animals were kept under standardised conditions, and tap water and mouse chow were provided ad libitum.

All experimental procedures were performed in accordance with the University of Murcia, which approved institutional animal care guidelines.

\section{Determination of Anti-Factor Xa Activity and Antigenic Levels of Antithrombin}

Antithrombin activity in plasma was determined using a commercial chromogenic (S-2765) anti-factor Xa (FXa) assay with heparin (Instrumentation Laboratory, Milano, Italy). Antithrombin antigen in plasma samples (from patients and mice) and medium samples were measured by electroimmunodiffusion (Laurell), a technique that is able to detect all forms of antithrombin. Values were expressed as percentage of the basal or control levels (100\%).

\section{Detection of Conformational Variants of Antithrombin in Plasma from Patients and Mice}

SDS-PAGE was performed in $8 \%(\mathrm{w} / \mathrm{v})$ polyacrylamide gels, running plasma from patients and mice, as described previously. ${ }^{12}$ Additionally, non-denaturing PAGE was performed as indicated elsewhere, with minor variations. ${ }^{13}$ Addition of $6 \mathrm{M}$ urea to the native gel allows differentiation of the native and latent forms of antithrombin, as reported. ${ }^{14}$ Plasma proteins were blotted onto PVDF membranes. Immunostaining was carried out with a rabbit anti-human antithrombin polyclonal antibody that recognises both human and mouse antithrombin (Dako Diagnostics, Golstrup, Denmark), followed by mouse anti-rabbit IgG-horseradish peroxidase conjugate (Amersham Biosciences Ltd, Little Chalfont, UK) and detection of antithrombin by ECL (Amersham Biosciences Ltd). Densitometric analysis of bands was carried out using the Quantity-One software (Bio Rad, Denver, CO, USA). 


\section{Crossed Immunoelectrophoresis}

Antithrombin affinity to heparin was evaluated by means of bi-dimensional electrophoresis with heparin, using the reagents and following the conditions described previously by our group. ${ }^{15}$

\section{Detection of $\alpha 1$-Antitrypsin in Plasma from Patients}

Levels of plasma $\alpha 1$-antitrypsin in human plasma were determined by ELISA (Genway Biotech, San Diego, CA, USA), according to the manufacturer's instructions.

\section{Detection of Hepatic Proteins in HepG2 Cells and Livers from Mice Treated with Bortezomib Characterisation of the Heat Stress Response}

Snap-frozen livers were weighed, minced and homogenised into $10 \times$ volume ice-cold lysis buffer (LB) $(10 \mathrm{mM}$ Tris-HCl, $0.5 \mathrm{mM}$ DTT, $0.035 \%$ SDS, $1 \mathrm{mM}$ EGTA, $50 \mathrm{mM}$ sodium fluoride, $50 \mu \mathrm{M}$ sodium orthovanadate, $5 \mathrm{mM}$ benzamidine, and $20 \mathrm{mM}$ phenylmethylsulphonyl fluoride (PMSF)). Total homogenates were aliquoted and stored at $-70^{\circ} \mathrm{C}$. Similarly, HepG2 cells were extensively washed with sterile PBS and then lysated with $500 \mu \mathrm{l}$ of lysis buffer and stored at $-70^{\circ} \mathrm{C}$. Bradford assays (Bio Rad) were carried out to determine the protein concentrations.

SDS-PAGE was performed as indicated before, running $40 \mu \mathrm{g} /$ well of cell or liver lysates. For western blot analysis, we used 1:5000 polyclonal antibodies (rabbit anti-human antithrombin, rabbit anti-human $\alpha 1$-antitrypsin (Dako Diagnostics), or mouse anti-human $\beta$-tubulin, as a loading control (Abcam Ltd, Cambridge, UK)). Rabbit anti-human prothrombin (1:500) (Abcam Ltd) and rabbit anti-human fibrinogen (1:1000) (Dako Diagnostics) polyclonal antibodies were used to evaluate the intracellular levels of other secreted hepatic proteins.

For the detection of HSR-related proteins in livers from mice treated with bortezomib, we immunostained the membranes with either goat anti-human heat-shock protein 27 (Hsp27) or Hsp70 (1:500 in both cases), rabbit antihuman Hsp90 (1:1000) or rabbit anti-human ubiquitin (1:100) polyclonal antibodies (Santa Cruz Biotechnology Inc., CA, USA). All these antibodies display cross-reactivity for their respective murine proteins. This was followed by incubation with either goat anti-rabbit (Amersham Biosciences Ltd) or horse anti-goat IgG-horseradish (Vector Labs, Burlingame, CA, USA). Development of the bands was carried out by means of enhanced chemiluminescence (Amersham Biosciences Ltd).

\section{Immunofluorescence, Histological, and Histopathological Analysis}

Antithrombin and $\alpha 1$-antitrypsin immunofluorescence analysis in HepG2 cells was assessed as reported. ${ }^{16}$ Briefly, cells were rinsed with PBS and incubated with blocking solution (0.3\% Tween-PBS, 10\% FCS, 5\% BSA). Following this step, cells were incubated with rabbit anti-human antithrombin or anti- $\alpha 1$-antitrypsin $(1: 1000$ and $1: 250$, respectively; Dako Diagnostics) for $90 \mathrm{~min}$ and washed three times in $0.1 \%$ Tween-PBS. Cells were then incubated with a fluorescein-labelled anti-rabbit IgG secondary antibody (1:250; Vector Labs) for $1 \mathrm{~h}$, washed three times in $0.1 \%$ Tween-PBS, mounted in Vectashield mounting medium (Vector Labs) and observed using green fluorescence $($ excitation $=488 \mathrm{~nm}$; emission $=530 \mathrm{~nm})$.

Paraffin-embedded liver sections $(4 \mu \mathrm{m})$ were stained with haematoxylin (Panreac, Catelar del Vallès, Spain), counterstained with eosin (Panreac, Spain), dehydrated and mounted in Dpex mounting medium (Panreac, Spain) for light microscopy observation. To detect intracellular $\beta$-sheetmediated deposits of proteins, congo red (Merck, Darmstadt, Germany) staining was applied. Glycoproteic deposits were assessed by the appearance of periodic acid Schiff-positive deposits by using a PAS-amylase technique (Panreac). Cell viability was assessed by Hoescht staining (Sigma-Aldrich, UK) and numbers of nuclei were counted in eight random $40 \times$ fields under blue fluorescence (excitation $=365 \mathrm{~nm}$; emission $=465 \mathrm{~nm}$ ).

For antithrombin and $\alpha 1$-antitrypsin immunohistochemistry purposes, a peroxidase-antiperoxidase technique was carried out. ${ }^{16}$ Briefly, sections were rinsed and endogenous peroxidase was inhibited. Sections were incubated in blocking solution $(0.1 \%$ Tween-TBS, $10 \%$ FCS, $5 \%$ BSA) for $30 \mathrm{~min}$ and incubated with rabbit polyclonal antibodies: anti-human antithrombin or anti-human $\alpha 1$-antitrypsin (1:250 for both; Dako Diagnostics) for $90 \mathrm{~min}$. Additional sections were incubated overnight with goat antihuman Hsp27, goat anti-human Hsp70, rabbit anti-human Hsp90 or anti-human ubiquitin polyclonal antibodies (1:250 in all cases; Santa Cruz, CA, USA). Then the sections were washed three times in $0.1 \%$ Tween-TBS and incubated with 1:250 of either anti-rabbit (antithrombin, $\alpha 1$-antitrypsin, Hsp-90, and anti-ubiquitin: Vector Labs) or anti-goat (antiHsp-27, Vector Labs) biotin-labelled secondary antibodies, and signal amplified with an ABC Kit (Vector Labs). Sections were then washed two times in $0.1 \%$ Tween-TBS, once with $\mathrm{TB}$, rinsed, developed with 3,3'-diaminobenzidine $(0.5 \mathrm{mg} /$ ml) (Sigma-Aldrich, UK) in $50 \mathrm{mM} \mathrm{TB}$ (pH 7.6), counterstained with haematoxylin, dehydrated and mounted.

Additionally, for simultaneous detection of glycoproteins and antithrombin, an immunohistochemistry PAS-amylase technique was carried out. Briefly, after immunohistochemistry for antithrombin immediately, a standard PAS-amylase staining was performed.

\section{Electron Microscopy Studies}

Fixed samples (4\% glutaraldehyde) of livers from PS341treated or control mice were dehydrated in sequential gradients of ethanol. Samples were then infiltrated with increasing concentrations of LR White resin (Merck, Germany). Polymerisation of the resin was carried out under oxygen-free conditions for $24 \mathrm{~h}$ at $50^{\circ} \mathrm{C}$. Ultrathin sections 
were cut using a Leica ultramicrotome (Leica Microsystems, Heidelberg, Germany) at $50 \mathrm{~nm}$ onto copper grids (for ultrastructural analysis) or nickel grids (for immunogold labelling).

Copper grid sections were post-fixed with osmium tetroxide and then stained with uranyl acetate and lead citrate. Ultrastructural morphology of mouse liver was analysed using an EM-10 Zeiss transmission electron microscope (Zeiss, Oberkochen, Germany).

A colloidal gold immunostaining technique for antithrombin and $\alpha 1$-antitrypsin was used for nickel sections. Briefly, sections were rinsed and incubated in blocking solution $(0.1 \%$ Tween-TBS, 10\% FCS, 5\% BSA) for $45 \mathrm{~min}$ and incubated with either, rabbit anti-human antithrombin or rabbit anti-human $\alpha 1$-antitrypsin polyclonal antibodies (1:250 for both; Dako Diagnostics) for $90 \mathrm{~min}$. Then, sections were washed three times in $0.1 \%$ Tween-TBS and incubated with $10 \mathrm{~nm}$ protein A-conjugated colloidal gold in TweenTBS (1:40) (Sigma-Aldrich, UK). Nickel grid sections were post-fixed with osmium tetroxide and then stained with uranyl acetate and lead citrate. Immunogold labelling was analysed with the EM-10 Zeiss transmission electron microscope (Zeiss, Germany).

\section{Genotyping of $Z$ and $S$ Alleles of $\alpha 1$-Antitrypsin}

Genomic DNA was extracted from whole blood from patients following the instructions of the Wizard ${ }^{\circledR}$ genomic DNA purification system (Promega). Primers, PCR conditions, and restriction enzymes used for the identification of $Z$ and $S$ $\alpha 1$-antitrypsin alleles were described elsewhere with minor modifications. ${ }^{17}$

\section{Statistical Analysis}

Results are presented as mean values \pm s.e.m. Unpaired $t$-tests were used for statistical significance determination purposes. Statistics were performed using GraphPad Prism, Version 4.0 (San Diego, CA, USA). A $P$-value $<0.05$ was considered statistically significant.

\section{RESULTS}

\section{In Vitro Effects of Bortezomib on Mature Antithrombin}

To test the direct effect of bortezomib on mature antithrombin, plasma samples from healthy donors $(n=4)$ and human purified antithrombin (up to $7.5 \mathrm{mg} / \mathrm{ml}$ ) were incubated at $37^{\circ} \mathrm{C}$ for $24 \mathrm{~h}$ with a wide range of concentrations of bortezomib (from $1 \mu \mathrm{M}$ up to $100 \mu \mathrm{M}, 10$ times the amount of bortezomib received by MM patients) or sterile PBS. In vitro treatment of these samples with bortezomib did not affect either antigen levels or the anti-FXa anticoagulant activity of antithrombin. Moreover, this incubation did not modify either the heparin affinity or the electrophoretic mobility of antithrombin in SDS-PAGE (data not shown). Additionally, bortezomib in vitro did not increase the levels of the latent form of antithrombin (a hyperstable conformer of the molecule in which the uncleaved reactive centre loop of the molecule is inserted into its own $\beta$-sheet A), ${ }^{18}$ and did not cause polymerisation of this serpin.

\section{Effects of Bortezomib on Circulating Antithrombin from Patients with MM}

Patients treated with bortezomib had antithrombin levels in plasma within the normal ranges (70-120\%), although this treatment produced a mild reduction of both antigen levels and anti-FXa activity (Figure 1a). Interestingly, a mild progressive increase in the circulating latent form of antithrombin was detected as the treatment progressed in these patients (Figure 1b), without formation of polymeric forms (data not shown).

\section{Effects of Bortezomib Treatment on HepG2 Cells}

As a first attempt to describe the effects of bortezomib on intracellular serpins, human hepatoma HepG2 cells were treated with either bortezomib at different concentrations $(10$ or $50 \mu \mathrm{M})$ or sterile PBS for $24 \mathrm{~h}$. The lowest concentrations of bortezomib used to treat the cells $(10 \mu \mathrm{M})$ were bioequivalent to those found in the plasma of $\mathrm{MM}$ patients treated with this drug. ${ }^{19}$ Untreated HepG2 cells had a round shape were basophilic with cytoplasms displaying a 'foamy-like appearance and their nuclei were homochromatinic. At $24 \mathrm{~h}$ post-bortezomib treatment, cytoplasms of cells shrunk and acquired a vacuolised appearance, and nuclei became more heterochromatinic. Moreover, bortezomib treatment produced a significant dose-dependent decrease of the levels of antithrombin secreted to the medium by HepG2 cells when compared to control PBS-treated cells (Figure 2a). Impaired secretion was not due to cell death, since Hoescht staining did not reveal cell death until $36 \mathrm{~h}$ post-treatment (data not shown). Western blots of cell lysates revealed that bortezomib caused intracellular retention of antithrombin (Figure 2b). Finally, in bortezomib-treated cells, immunofluorescent labelling of antithrombin revealed the re-localisation of the widespread diffuse antithrombin into more intense clusters (Figure 2c), suggestive of aggregates. Interestingly, the effects of bortezomib on the intracellular retention/aggregation of antithrombin were similar for other conformationally sensitive hepatic serpins, such as $\alpha 1$-antitrypsin, as shown in Figure 2 c.

\section{Bortezomib Treatment of Mice}

Effects of bortezomib on circulating antithrombin

The mouse model accurately reproduced the effects of bortezomib treatment in MM patients. Indeed, plasma of mice treated with bortezomib revealed only minor decreases in both the anticoagulant anti-FXa activity and antigen levels of antithrombin (Figure 3a). However, when assessing the effects of cumulative doses of bortezomib on circulating antithrombin by injecting bortezomib into mice for two consecutive days (days +5 and +6 ), the decrease in both parameters became significant (Figure 3a). 
a

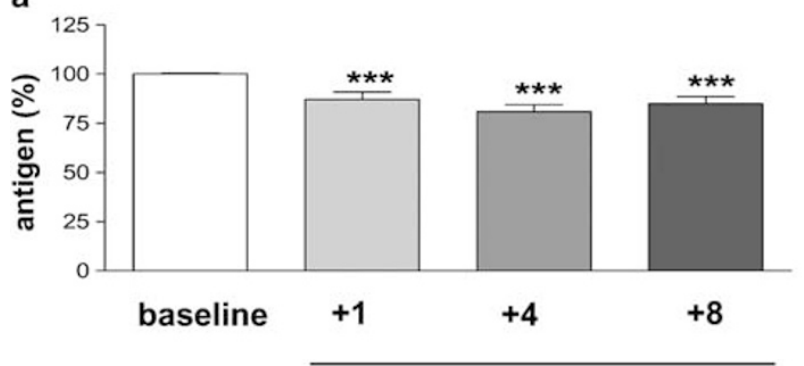

bortezomib

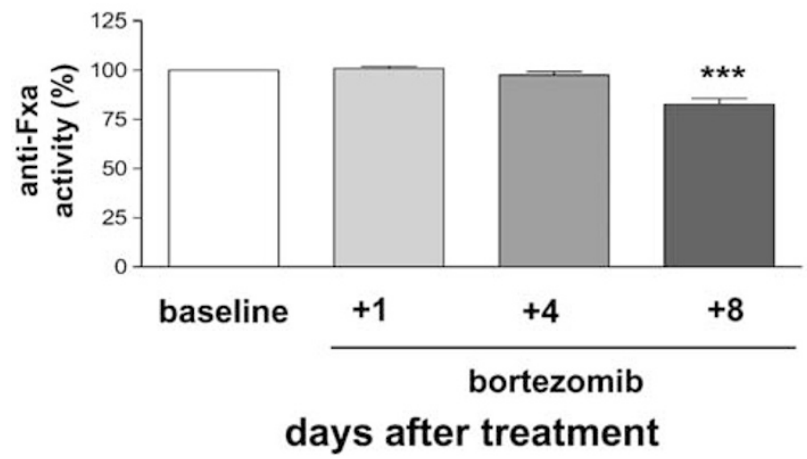

b

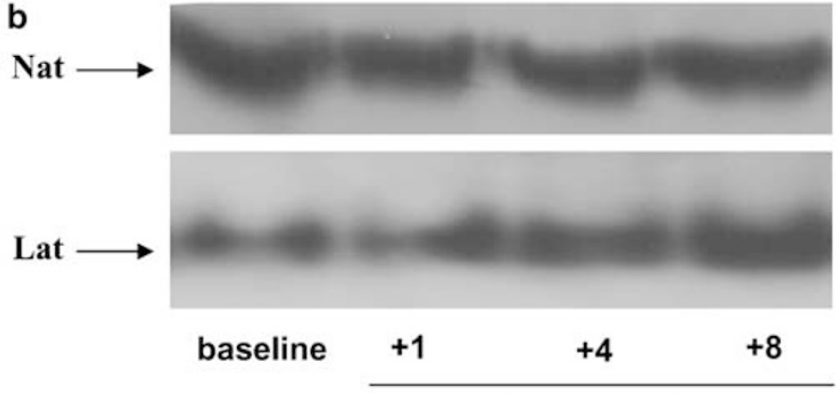

bortezomib

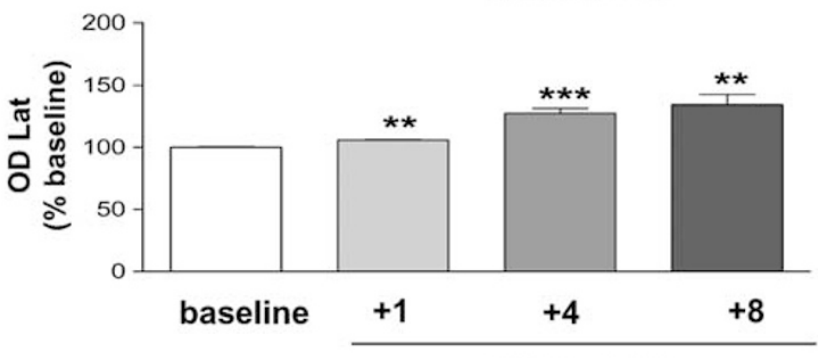

bortezomib

days after treatment

Figure 1 Circulating antithrombin in MM patients $(N=7)$ treated with bortezomib. (a) Time-dependent effects of bortezomib on the plasma antigen and anti-FXa anticoagulant function levels. (b) Representative blots of both, native (Nat) and latent (Lat) antithrombin as revealed by native-PAGE without (native) or with $6 \mathrm{M}$ urea (latent) and immunoblotting. Levels of the latent circulating form of antithrombin were quantified by optical densitometry of the gels. Results are presented as percentages of their baseline levels as means \pm s.e.m. $\left({ }^{* * P}<0.01 ;{ }^{* *} P<0.001\right)$.

Moreover, reproducing the results seen in human MM patients, no differences in the molecular weight or polymeric forms of circulating antithrombin were detected in the plasma of mice treated with bortezomib (data not shown). Similarly, a progressive increase of the latent form of antithrombin was detected with the progression of the treatment with bortezomib (Figure $3 \mathrm{~b}$ ).

\section{Effects of Bortezomib Treatment on Livers}

Inhibition of the proteasome with bortezomib produced vacuolar and fat degeneration of livers in mice (Figure 4). The appearance of these vacuoles was associated with a progressive increase in intracellular congo red-positive $\beta$-amyloid and PAS-amylase-positive glycoprotein deposits, and Mallory body formation (Figure 4). Mallory bodies are aggresomes of ubiquitinated cytokeratin- 8 and cytokeratin18 proteins. Among other proteins, Mallory bodies have been shown to recruit Hsp70, Hsp90, tubulin, mutated ubiquitin $\left(\mathrm{UBB}^{1+}\right)$, transglutaminase, proteasomal $26 \mathrm{~S}$ subunits, p62, and isoforms of tau, among others. ${ }^{20}$ Similarly to the results observed in HepG2 cells, bortezomib treatment altered the morphology of the hepatocyte, by inducing vacuolar degeneration and enlargement of the cell bodies and nuclei on day +5 (Figure 4). Significant cell death was not observed at this stage (data not shown). Additionally, electron microscopy studies of livers from bortezomib-treated mice revealed mild dilation of the rough endoplasmic reticulum (ER) cisternae- containing electrodense material that progressed into confronting cisternae-like organelles (for detail, see Figure $4 \mathrm{~b}$ ) and Mallory body formation in some cases (Figure 4).

Intracellular effects of bortezomib treatment on antithrombin and other hepatic proteins

We also evaluated a possible intracellular retention and aggregation of antithrombin in livers of mice treated with bortezomib. SDS-PAGE immunoblotting revealed progressive intracellular accumulation of antithrombin, as demonstrated by the increased amount of antithrombin in liver extracts from bortezomib-treated animals (Figure 5a). Moreover, immunohistochemistry studies revealed the progressive intracellular retention and formation of aggregates of antithrombin in bortezomib-treated mice (Figure 5b). Furthermore, an anti-antithrombin immunostaining PASamylase assembled technique suggests that antithrombin might be associated to Mallory bodies (Figure 5b). Finally, immunogold labelling confirmed the retention and aggregation of this serpin within the lumen of some dilated rough ER cisternae of bortezomib-treated mice, and further suggests its association to some Mallory bodies (Figure $5 \mathrm{c}$ ).

As shown for HepG2 cells, bortezomib effects were not restricted to antithrombin, but also affected $\alpha 1$-antitrypsin. Indeed, SDS-PAGE immunoblotting revealed a progressive increase in the levels of retained intracellular $\alpha 1$-antitrypsin as the treatment with bortezomib progressed (Figure 5a). 
a

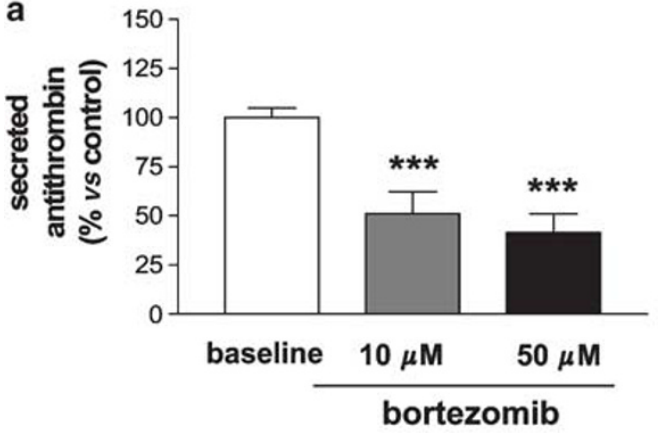

b

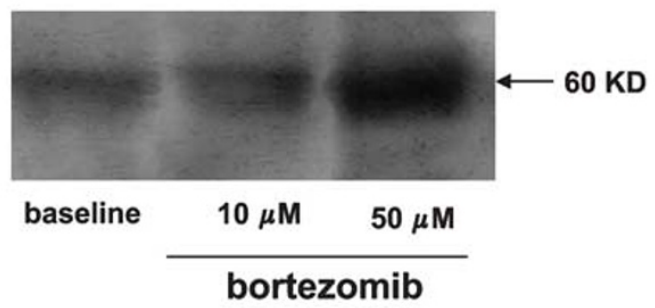

C
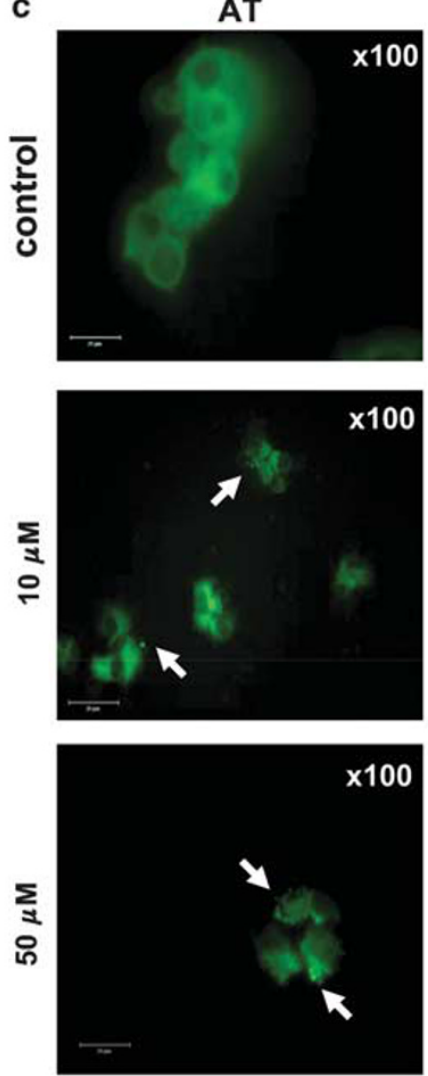

$\alpha 1-\mathrm{AT}$
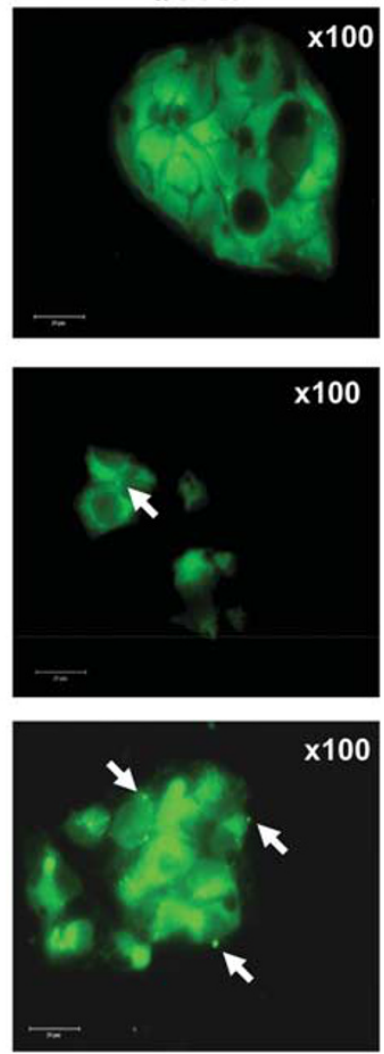

Figure 2 Effects of bortezomib on human hepatoma HepG2 cells after $24 \mathrm{~h}$ of incubation. (a) Secretion of antithrombin from HepG2 cells into the tissue culture medium. Results are presented as means \pm s.e.m. of five different experiments $(* * * P<0.001)$. (b) Dose-dependent accumulation of intracellular antithrombin, as detected by SDS-PAGE and immunoblotting. (c) Dose-dependent effects of the drug on intracellular antithrombin and $\alpha 1$-antitrypsin as revealed by indirect immunofluorescence. Arrows indicate intracellular accumuli of antithrombin (AT) or $\alpha 1$-antitrypsin ( $\alpha 1$-AT).

These results were confirmed by using immunohistochemical staining of the protein that revealed the intracellular retention of the protein as well as a more discrete intracellular accumulation (Figure 5b) that, in most cases, was located within dilated ER cisternae (Figure 5c).

Finally, two different controls of different secreted hepatic proteins were used. Prothrombin is not sensitive to most conformational agents, including mutations. ${ }^{21-23}$ The intracellular level of prothrombin was not significantly increased within the livers of bortezomib-treated mice (Figure $5 \mathrm{a}$ ). On the other hand, fibrinogen, a non-serpin but conformationally sensitive protein, ${ }^{23}$ was intrahepatically retained (Figure 5a). Fibrinogen $\alpha$ - and $\gamma$-chains were the most affected (Figure 5a). Interestingly, these chains have more conformational sensitivity according to the number of mutations associated with congenital afibrinogenemia, hypofibrinogenemia, or dysfibrinogenemia. ${ }^{23-24}$

\section{Bortezomib caused a hepatic HSR}

To evaluate the cell response to the intracellular accumulation of proteins, we evaluated the levels and intracellular localisation of the three main heat-stress-induced molecular chaperones (Hsp27, Hsp70, and Hsp90) and ubiquitin.
Bortezomib treatment has been previously shown to elicit an unfolded protein response (UPR) in MM cells due to protein misfolding that could develop into an HSR. ${ }^{25}$ Moreover, patients with different liver diseases and 'drug-primed' mice that develop Mallory bodies also present an HSR. ${ }^{26-28}$ Indeed, bortezomib caused an HSR in our mouse model. Figure 6a displays representative images of our findings. Immunohistochemistry of Hsp27 revealed a change from the widespread punctuate-like pattern distribution of this heat-shock protein into a clustered-like pattern, probably surrounding protein aggregates after the whole protocol of treatment with bortezomib (Figure 6a). The inducible Hsp70, barely visible in control mice, increased in expression and also adopted a clustered-like appearance distributed in most occasions next to the nuclear membrane (Figure 6a). Hsp90, which formed small perinuclear clusters in control animals, in treated animals formed bigger perinuclear clusters or became intranuclear (Figure 6a). Finally, ubiquitin, the main molecule responsible for the targeting of misfolded proteins to the proteasome for degradation, had its expression enhanced and also formed aggregates in some occasions (Figure 6a), as described previously. ${ }^{10}$ These results were validated by immunoblotting with the respective antibodies, 

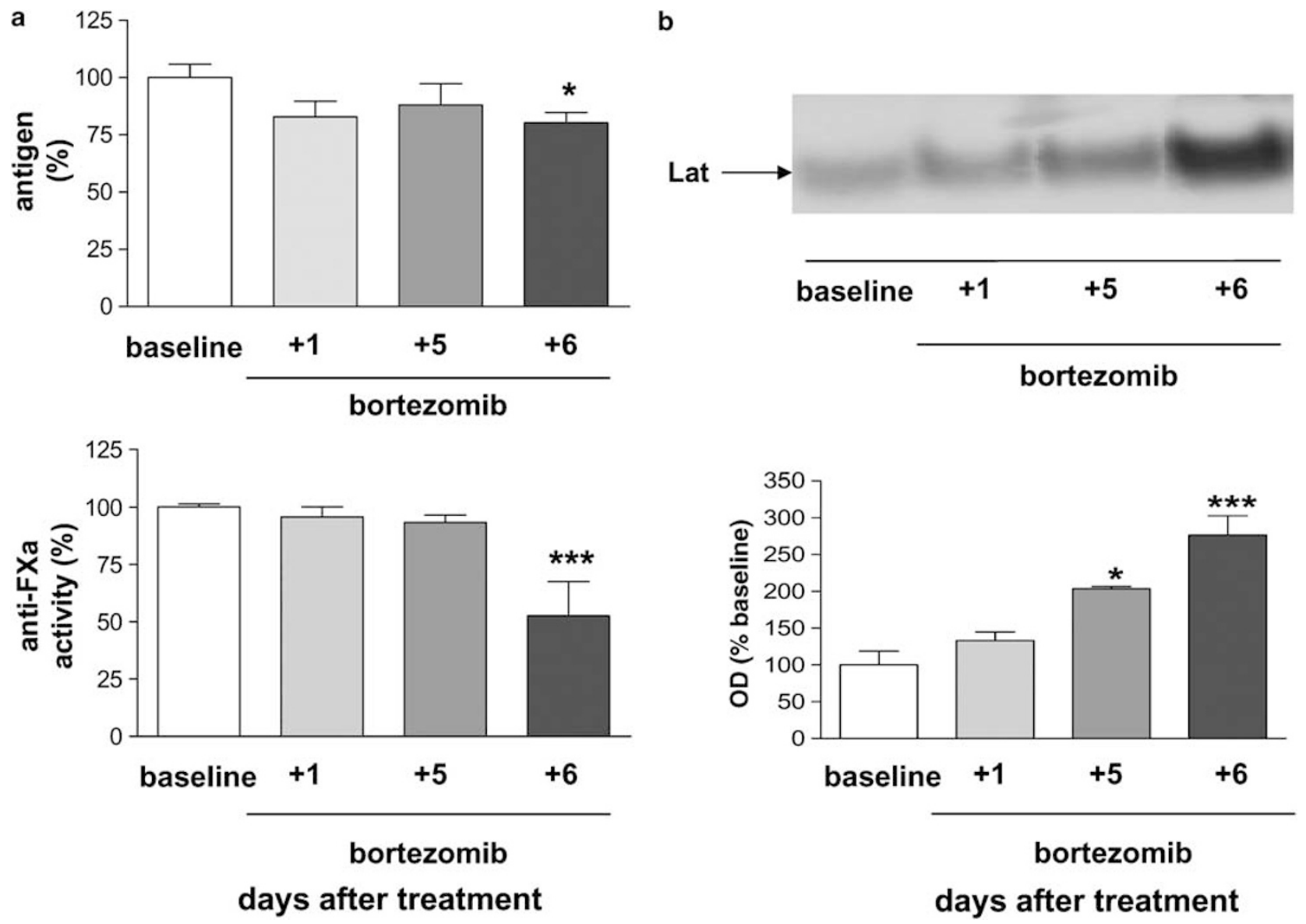

Figure 3 Circulating antithrombin in mice treated with bortezomib. (a) Time-dependent effects of bortezomib on the antigen and anti-FXa anticoagulant function levels of antithrombin in plasma. (b) Levels of the latent circulating form of antithrombin as revealed by native PAGE with $6 \mathrm{M}$ urea and immunoblotting (Lat, latent) quantified by optical densitometry of the gels. Results are presented as percentages of their baseline levels as means \pm s.e.m. of five different experiments $\left({ }^{*} P<0.05 ;{ }^{* *} P<0.001\right)$.

which demonstrate a time-dependent intrahepatic increase in the levels of all the chaperones (Hsp27, Hsp70, and Hsp90) and ubiquitinated proteins, particularly high-molecular weight complexes of ubiquitin and proteins (Figure 6b).

\section{Effects of Bortezomib Treatment on Circulating a1-Antitrypsin: Putative Clinical Consequences and Possible Potentiation by Conformational Polymorphisms}

Levels of $\alpha 1$-antitrypsin were studied in seven MM patients treated with bortezomib. Bortezomib did not cause a significant reduction in their circulating levels of $\alpha 1$-antitrypsin. However, a trend to a decrease in their circulating levels was detected (basal: $2606 \pm 226 v s$ day $+8: 2151 \pm 542 \mathrm{ng} / \mathrm{ml}$ ). No patient developed severe hepatotoxicity, pulmonary, or neurological complications during the treatment.

To evaluate the possible role of conformational polymorphisms affecting this serpin on the side effects of bortezomib, we retrospectively genotyped the $\mathrm{S}$ and $\mathrm{Z}$ variants in $34 \mathrm{MM}$ patients treated with this drug, and evaluated the clinical features, both at hepatic and pulmonary levels. Two patients were heterozygous for the $S$ form, but they did not report hepatotoxicity or pulmonary complications. Interestingly, only one patient carried the Z-antitrypsin variant in heterozygosity. This patient did not show hepatotoxicity during the treatment, but he developed respiratory insufficiency during the treatment, which was complicated with a subsequent infection.

\section{DISCUSSION}

Conformational diseases include dementia such as Alzheimer's, Parkinson's and the prion spongiform encephalopathies; amyloidoses, emphysema, and thrombosis, among many other disorders. ${ }^{29}$ These diseases, although heterogeneous in origin, share common features in their pathological mechanisms with each other. In all cases, a conformational change in the underlying protein leads to an intermolecular linkage and aggregation. One of the main contributing factors to a number of conformational diseases is the impairment of the ubiquitin-proteasome system. ${ }^{10}$ Additionally, a relevant group of proteins involved in conformational diseases, and the best-studied example 

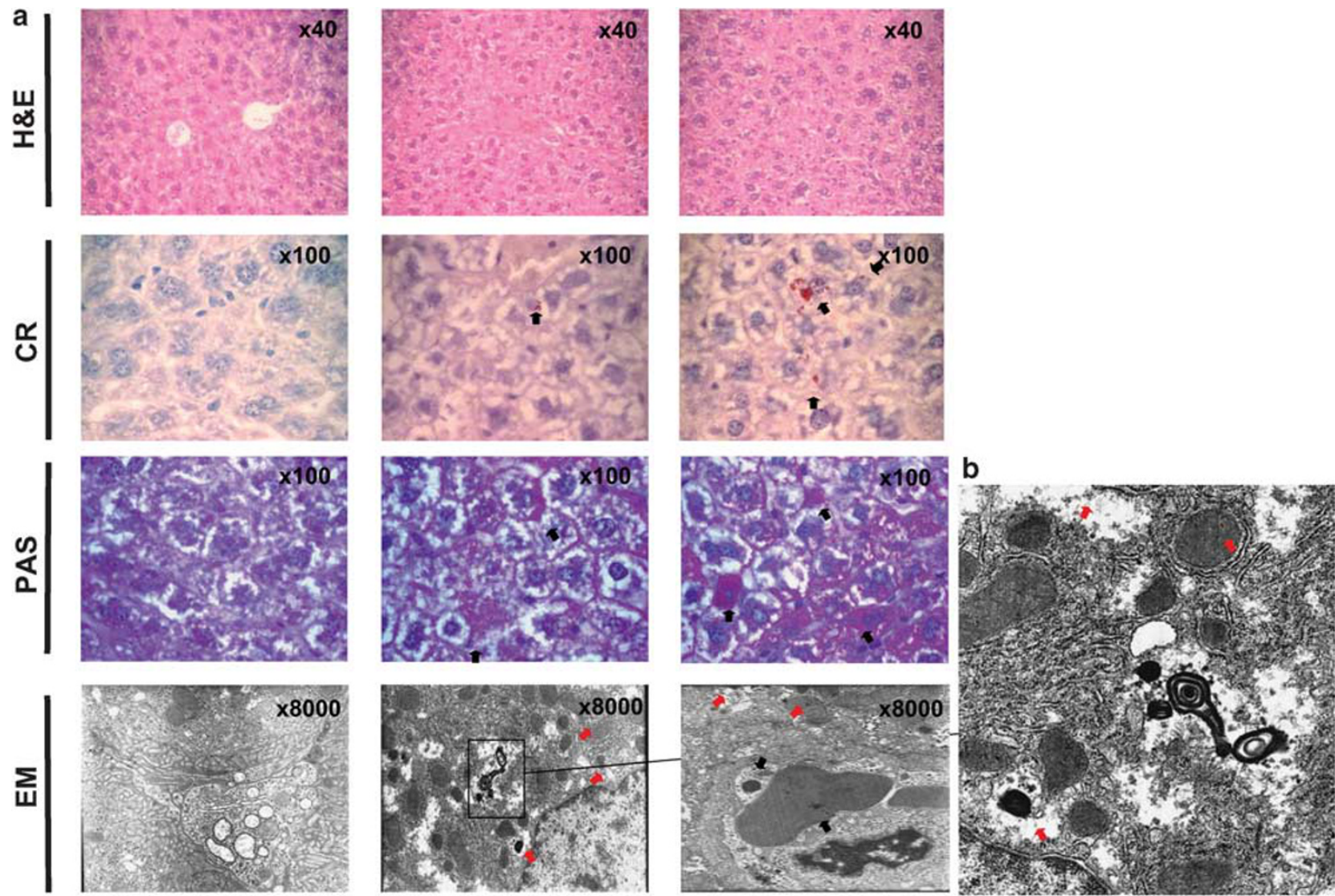

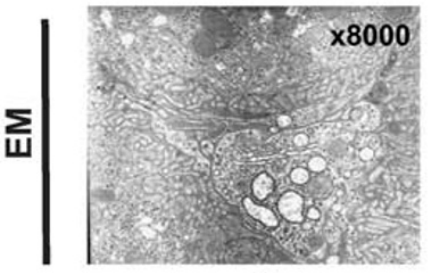

0

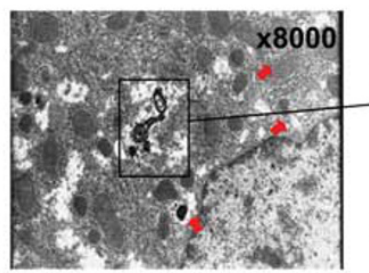

$+5$

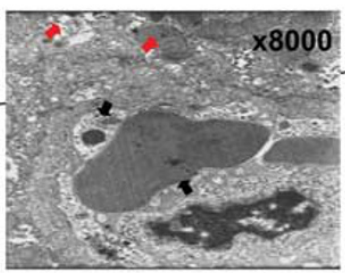

$+6$

days of treatment

Figure 4 Time-dependent histological and ultrastructural effects of bortezomib on mice livers. (a) Haematoxylin and eosin ( $\times 40$ magnification), congo red (CR) (featuring $\beta$-amyloid deposit staining) and amylase-PAS (PAS) (featuring glycoprotein accumuli) $(\times 100$ magnification in both cases) under light microscopy. Additionally, transmission electron microscopy $(E M)$ revealed ultrastructural features of bortezomib-treated hepatocytes from mice $(\times 8000$ magnification). Black arrows indicate the presence of intracellular Mallory bodies and/or glycoprotein deposits. Red arrows indicate areas of dilated ER cisternae. (b) Digital amplification of confronting cisternae and dilated ER from a mouse treated with bortezomib for 4 days under electron microscopy. Red arrows indicate areas of dilated ER cisternae.

in terms of the structural changes being involved, is the serpin superfamily. ${ }^{2}$ In this framework, the study of conformational effects of proteasome inhibitors on serpins is extremely interesting, particularly since the therapeutic use of proteasome inhibitors, such as bortezomib, has significantly increased within the last few years. ${ }^{11}$ As a model, we studied antithrombin, a hepatic haemostatic serpin that has relevant conformational sensibility to point mutations $^{18}$ and to environmental stimuli such as L-asparaginase drug treatment, hyperlipidemia, and hyperthermia. ${ }^{16,30,31}$

As expected, our in vitro studies revealed that bortezomib had no effect on the mature secreted antithrombin molecule. Moreover, patients or mice treated with bortezomib had antithrombin levels in plasma within the normal ranges, although this treatment produced a mild reduction in both antigen levels and anti-FXa activity. However, in this study, we demonstrate that inhibition of the proteasome by bortezomib has mainly significant consequences on presecreted nascent serpins, as previously shown for other environmental stimuli. ${ }^{16,30,31}$ Thus, bortezomib caused intracellular aggregation of antithrombin and other hepatic serpins ( $\alpha 1$-antitrypsin) within dilated cisternae of the ER. If high percentages of proteins are normally misfolded within cells, ${ }^{3}$ it is not surprising to find a significant inefficient folding rate of conformational sensitive serpins, even under normal conditions. ${ }^{32}$ These abnormally folded proteins are targeted via the ER quality control system for degradation. ${ }^{33}$ One of the key elements in this quality control system is the proteasome, that is going to degrade these misfolded protein conformers into small peptides. ${ }^{10}$ In cases of improper functioning of the cytosolic (proteasome and heat-shock proteins) and ER quality control systems (the former induced by bortezomib treatment), or when abnormal proteins contain high percentages of $\beta$-pleated sheets (as it occurs in most conformational disorders), the proteasome is unable to degrade these abnormal substrates, and this system becomes overloaded and clogged. ${ }^{3}$ The resulting unfolded proteins tend to be accumulated within dilated cisternae of the ER and 
a

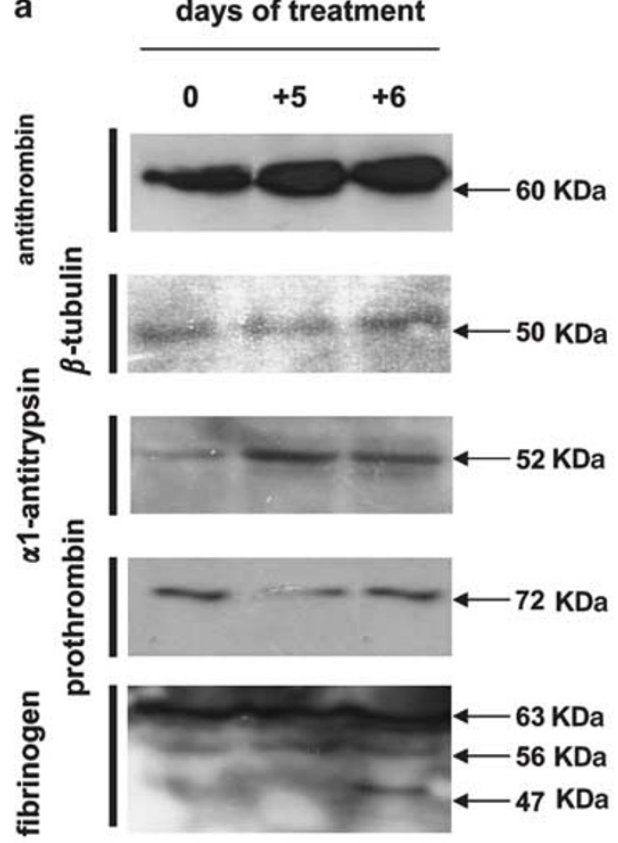

b
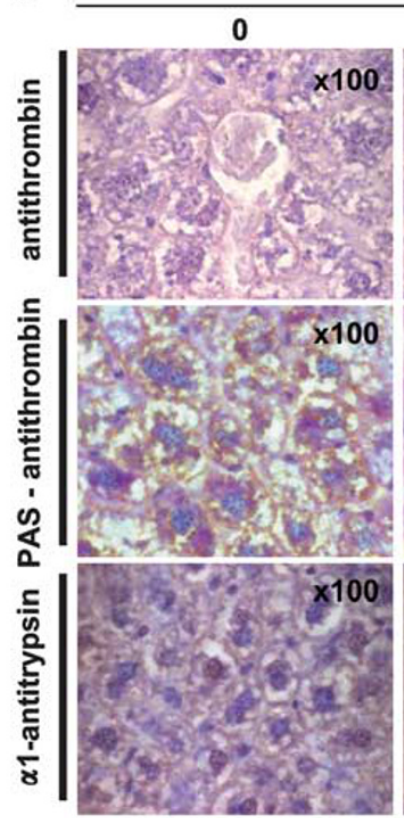

days of treatment
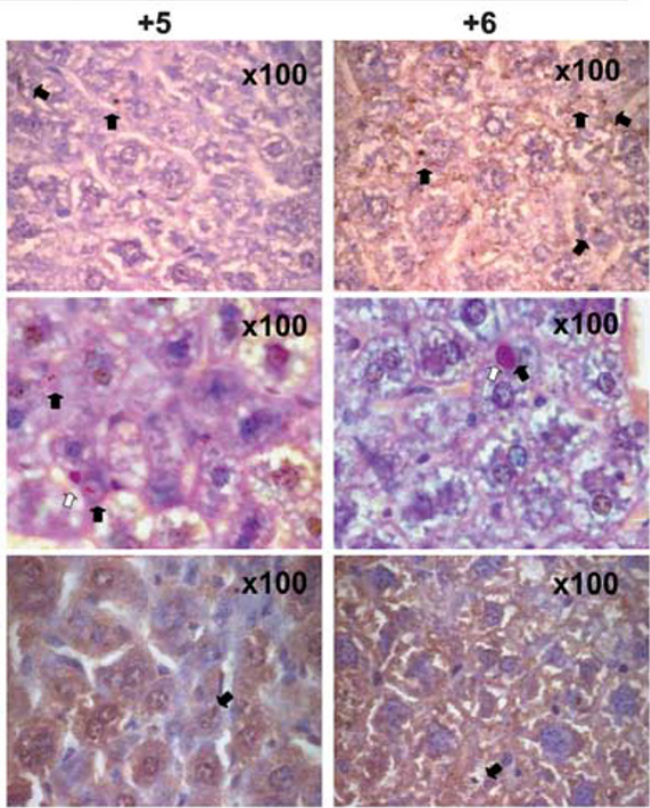

C

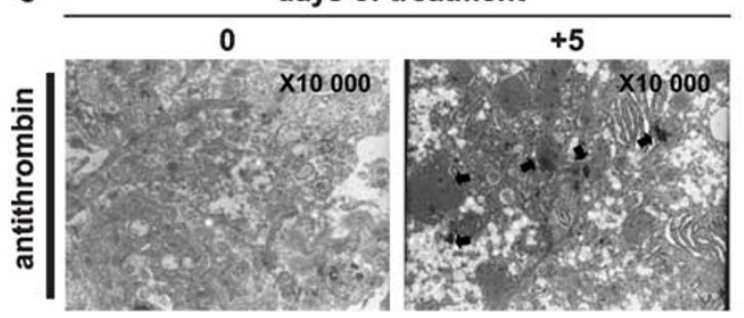

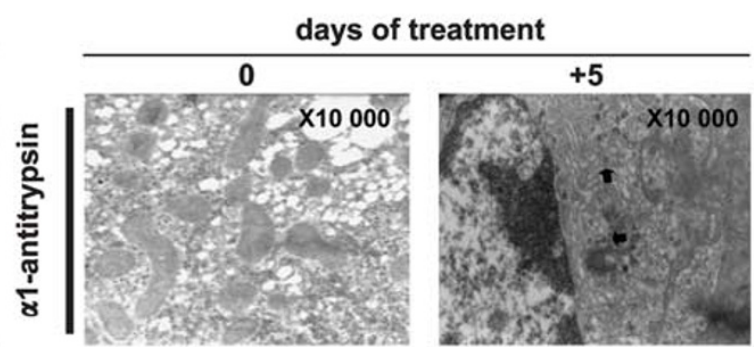

Figure 5 Time-dependent effects of bortezomib treatment on murine hepatic antithrombin, and $\alpha 1$ - antitrypsin. (a). Immunoblotting results of bortezomib treatment for antithrombin, $\alpha 1$-antitrypsin, $\beta$-tubulin as loading control, and prothrombin and fibrinogen as controls of other hepatically-secreted proteins. (b). Immunohistochemical results for antithrombin (alone and combined with an amylase-PAS staining) and $\alpha 1$-antitrypsin ( $\times 100$ magnification). Black arrows indicate antithrombin or $\alpha 1$-antitrypsin accumuli/aggregates; white arrows indicate Mallory bodies. (c) Ultrastructural distribution of antithrombin and $\alpha 1$-antitrypsin under transmission electron microscopy as revealed by immunogold labelling ( $\times 10000$ magnification). Arrows indicate antithrombin and $\alpha 1$-antitrypsin accumuli.

vacuoles, and aggregate under some circumstances forming, on many occasions, aggresomes. ${ }^{3}$ Indeed, aggresome formation has been experimentally described as a main consequence of the misfolding of proteins due to proteasome inhibition. ${ }^{34}$ In addition to this, our observation that antithrombin and $\alpha 1$-antitrypsin intracellularly accumulate and aggregate after bortezomib treatment further supports the requirement of a proteasome-dependent, ER-associated protein degradation machinery (ERAD) for the correct processing and quality control of serpins. ${ }^{4-9}$ All these results, together with similar findings for another conformationally sensitive protein such as fibrinogen, ${ }^{24}$ but minor consequences on non-structurally sensitive proteins such as prothrombin, support the notion that impairment of proteasome mainly affects conformationally sensitive proteins, leading to the intracellular accumulation of misfolded molecules. Moreover, the minor effect that bortezomib has on circulating proteins secreted from the liver, and the absence of intracellular accumulation of prothrombin, suggest that although the ER may be partially blocked with misfolded proteins, the secretion of properly folded proteins seems to be not significantly impaired, at least after 2 days of treatment. However, the secretion of proteins seems to be more impaired in mice treated consecutively with bortezomib during 2 days and in the cell model. Thus, it is possible that a prolonged inhibition of the proteasome might cause an ER clogging that impairs the secretion of any protein. Further studies are required to confirm the effect of extensive treatment with bortezomib.

We confirm that the inhibition of proteasome with bortezomib produces Mallory bodies. ${ }^{35,36}$ Additionally, this is the first time that confronting cisternae have been associated with bortezomib treatment. These organelles had been previously related only to severe liver diseases. ${ }^{37-40}$ Interestingly, our study presents the first evidence of the association of serpins to Mallory bodies. Thus, our results 
a
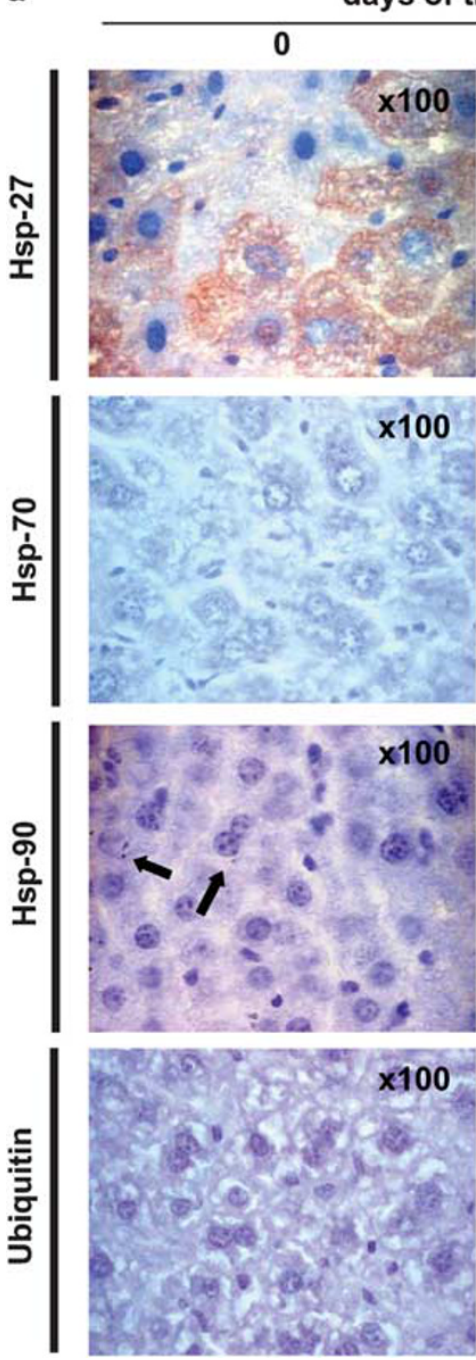

$+5$
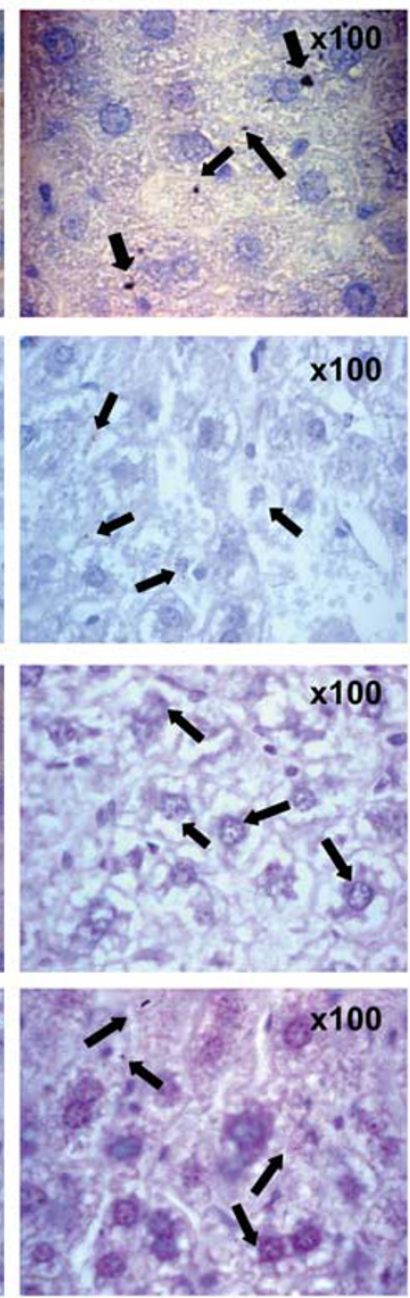

b
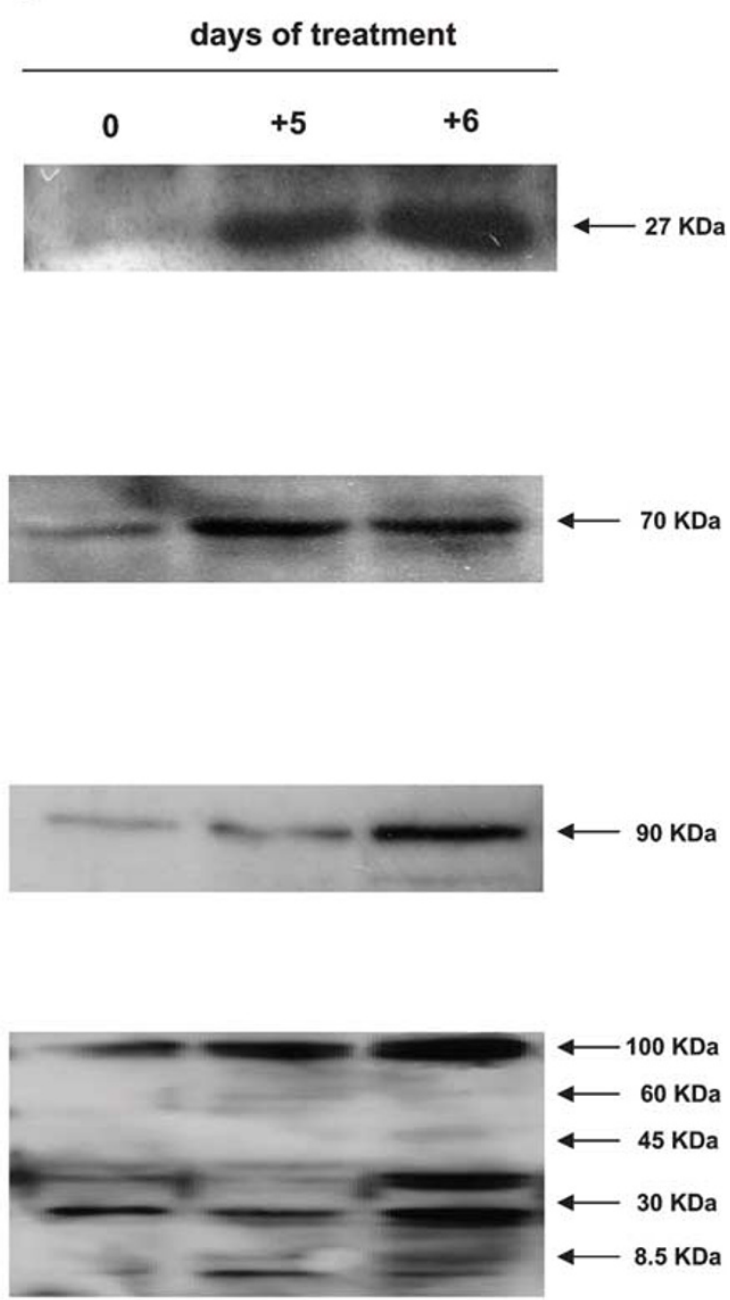

Figure 6 HSR on mice livers as produced by bortezomib treatment. Effects on Hsp27, Hsp70, Hsp90 and ubiquitin as shown by immunohistochemistry under light microscopy (a) ( $\times 100$ magnification) and representative blots after SDS-PAGE (b). Arrows on the immunohistochemistry images indicate intracellular accumuli of all the aforementioned proteins.

suggest that antithrombin might also be included in the list of proteins, beyond the classical cytokeratins, involved in Mallory body formation. ${ }^{34,35,41}$

When unfolded proteins are accumulated, especially under bortezomib treatment, a response in the cytosol occurs that induces the expression of Hsp27, Hsp70, and Hsp90 to prevent the retrograde translocation of additional unfolded proteins from the ER into the cytosol that works as a 'waste basket'. ${ }^{20,42}$ These chaperones have been previously associated to Mallory body formation in models of hepatocellular injury and human liver biopsy specimens with a number of diseases. $^{20,34,35,41}$ In accordance, it has been shown that bortezomib exerts terminal UPR and ER stress-induced apoptosis responses in $\mathrm{MM}$ cells in vitro. ${ }^{25}$ We confirm that the bortezomib-induced intracellular aggregation of proteins triggers an HSR by increasing expression and forming clusters of Hsp27, Hsp70 and Hsp90. Finally, overall expression of ubiquitin, the molecule responsible for the targeting of most proteins for proteasomal destruction, ${ }^{10}$ significantly increased, thus forming the previously described cytoplasmic and nuclear aggregates associated with Mallory bodies. ${ }^{34,41}$

Altogether, these results raise an interesting hypothesis: if the proteasomal function becomes impaired, abnormally folded proteins are not properly degraded intracellularly, and a low percentage of these proteins might be secreted. These abnormally folded proteins might promptly adopt more stable conformations as the latent form of antithrombin, similarly to that described for certain antithrombin mutants that have conformational consequences. ${ }^{43-45}$ Indeed, even the correctly folded native antithrombin spontaneously transforms under normal conditions to the latent conformation, probably as a senescence mechanism. ${ }^{14,46}$ This might explain the increased levels of the circulating latent form of antithrombin detected in both human MM patients and mice 
treated with bortezomib. These forms have no inhibitory function, but might acquire new functions, ${ }^{47}$ and their role in these patients warrants further investigation.

Under the scheme used in patients, the conformational modifications caused by bortezomib in structurally sensitive proteins such as hepatic serpins may not be associated with adverse side effects of this drug. We speculated that the conformational effects associated with bortezomib treatment might be exacerbated by combination with additional conformational factors. We evaluated the effect of the archetypal example of a conformational disease: the deficiency of the plasma serpin $\alpha 1$-antitrypsin (common among people of European descent). The consequence of this missense polymorphism (Glu342Lys, responsible for the $\mathrm{Z}$ form of $\alpha 1$-antitrypsin) is an instability of folding such that the reactive loop of one molecule can insert into a $\beta$-sheet of another to give sequential formation of long bead-like polymers of the abnormal $\alpha 1$-antitrypsin. ${ }^{32}$ The intracellular accumulation of polymers in the liver may lead eventually to cirrhosis. ${ }^{32}$ Moreover, the combination of the misfolding and the intracellular accumulation of polymers result in grossly reduced secretion of the protein and hence in plasma deficiency, which may cause pulmonary emphysema. ${ }^{32}$ In this framework, the treatment with bortezomib of carriers of the $\mathrm{Z}$ (and to a lesser extent, carriers of the S) $\alpha 1$-antitrypsin variants might exacerbate the conformational effects and might potentially contribute to some of the bortezomib-derived side effects, such as severe hepatitis, thromboembolism, peripheral neurotoxicities, or severe pulmonary complications. ${ }^{48-51}$ It is interesting to notice that the only one patient with the $\mathrm{Z}$ form of $\alpha 1$-antitrypsin presented pulmonary complications during the treatment. Further studies including more patients in prospective studies with determination of circulating $\alpha 1$-antitrypsin levels are required to sustain any deleterious effect of this treatment in patients under additional conformational stressors. Finally, we speculate that increasing doses or time of treatment, as well as the combination with more severe conformational factors (such as homozygous Z-antitrypsin), or combination with other drugs such as thalidomide (with known prothrombotic potential), ${ }^{52}$ might exacerbate the conformational effects of bortezomib with potential pathological consequences.

\section{ACKNOWLEDGEMENT}

This project has been supported by Fundación Séneca (Grants 00583/PI/04 and 00603/PI/04), SAF2006-06212 (MEC \& FEDER) and RETICS (RECAVA) from ISCIII. David-Hernández-Espinosa, Adriana Ordóñez, and Rubén Mota are FIS/FFIS investigators. CM is a Ramón y Cajal investigator at the University of Murcia.

1. Carrell RW, Huntington JA. How serpins change their fold for better and for worse. Biochem Soc Symp 2003;70:163-178.

2. Lomas DA, Carrell RW. Serpinopathies and the conformational dementias. Nat Rev Genet 2002;3:759-768.

3. Meusser B, Hirsch $C$, Jarosch $E$, et al. ERAD: the long road to destruction. Nat Cell Biol 2005;7:766-772.
4. Carrell RW. Cell toxicity and conformational disease. Trends Cell Biol 2005; 15:574-580.

5. Tokunaga F, Shirotani H, Hara $\mathrm{K}$, et al. Intracellular degradation of secretion defect-type mutants of antithrombin is inhibited by proteasomal inhibitors. FEBS Lett 1997;412:65-69.

6. Shirotani H, Tokunaga $\mathrm{F}$, Koide T. Cellular and functional characterization of three recombinant antithrombin mutants that caused pleiotropic effect-type deficiency. J Biochem (Tokyo) 1999;125:253-262.

7. Wu Y, Swulius MT, Moremen KW, et al. Elucidation of the molecular logic by which misfolded alpha 1-antitrypsin is preferentially selected for degradation. Proc Natl Acad Sci USA 2003;100:8229-8234.

8. Teckman JH, Burrows J, Hidvegi T, et al. The proteasome participates in degradation of mutant alpha 1-antitrypsin $Z$ in the endoplasmic reticulum of hepatoma-derived hepatocytes. J Biol Chem 2001;276:44865-44872.

9. Miranda $\mathrm{E}$, Romisch K, Lomas DA. Mutants of neuroserpin that cause dementia accumulate as polymers within the endoplasmic reticulum. J Biol Chem 2004;279:28283-28291.

10. Ciechanover A. Intracellular protein degradation: from a vague idea thru the lysosome and the ubiquitin-proteasome system and onto human diseases and drug targeting. Cell Death Differ 2005;12:1178-1190.

11. Richardson PG, Mitsiades C. Bortezomib: proteasome inhibition as an effective anticancer therapy. Future Oncol 2005;1:161-171.

12. Bruce D, Perry DJ, Borg J-Y, et al. Thromboembolic disease due to thermolabile conformational changes of antithrombin Rouen-VI (197 Asn-Asp). J Clin Invest 1994;94:2265-2274.

13. Zhou A, Huntington JA, Carrell RW. Formation of the antithrombin heterodimer in vivo and the onset of thrombosis. Blood 1999;94: 3388-3396.

14. Mushunje A, Evans G, Brennan SO, et al. Latent antithrombin and its detection, formation and turnover in the circulation. J Thromb Haemost 2004:2:2170-2177.

15. Corral J, Rivera J, Martinez C, et al. Detection of conformational transformation of antithrombin in blood with crossed immunoelectrophoresis: new application for a classical method. J Lab Clin Med 2003;142:298-305.

16. Hernandez-Espinosa D, Minano A, Martinez C, et al. L-asparaginaseinduced antithrombin type I deficiency: implications for conformational diseases. Am J Pathol 2006;169:142-153.

17. Braun A, Meyer $P$, Cleve $H$, et al. Rapid and simple diagnosis of the two common a1-proteinase inhibitor deficiency alleles $\mathrm{P} 1{ }^{*} \mathrm{Z}$ and $\mathrm{Pi}^{*} \mathrm{~S}$ by DNA analysis. Eur J Clin Chem Clin Biochem 1996;34:761-764.

18. Corral J, Vicente V, Carrell RW. Thrombosis as a conformational disease. Haematologica 2005;90:238-246.

19. Richardson PG, Barlogie B, Berenson J, et al. A phase 2 study of bortezomib in relapsed, refractory myeloma. N Engl J Med 2003;348:2609-2617.

20. Riley NE, Li J, McPhaul LW, et al. Heat shock proteins are present in Mallory bodies (cytokeratin aggresomes) in human liver biopsy specimens. Exp Mol Pathol 2003;74:168-172.

21. Swanson JC, Suttie JW. Prothrombin biosynthesis: characterization of processing events in rat liver microsomes. Biochemistry 1985;24: 3890-3897.

22. Uehara S, Gotoh $\mathrm{K}$, Handa $\mathrm{H}$, et al. Process of carboxylation of glutamic acid residues in the gla domain of human des-gammacarboxyprothrombin. Clin Chim Acta 1999;289:33-44.

23. The Human Gene Mutation Database at the Institute of Medical Genetics in Cardiff. http://www.hgmd.cf.ac.uk.

24. Vu D, Neerman-Arbez M. Molecular mechanism accounting for fibrinogen deficiency: from large deletions to intracellular retention of misfolded proteins. J Throm Hemost 2007;5(Suppl 1):125-131.

25. Obeng EA, Carlson LM, Gutman DM, et al. Proteasome inhibitors induce a terminal unfolded protein response in multiple myeloma cells. Blood 2006;107:4907-4916.

26. VanSlyke JK, Musil LS. Dislocation and degradation from the ER are regulated by cytosolic stress. J Cell Biol 2002;157:381-394.

27. Bush KT, Goldberg AL, Nigam SK. Proteasome inhibition leads to a heat-shock response, induction of endoplasmic reticulum chaperones, and thermotolerance. J Biol Chem 1997;272:9086-9092.

28. Kim D, Kim SH, Li GC. Proteasome inhibitors MG132 and lactacystin hyperphosphorylate SF1 and induce hsp70 and hsp27 expression. Biochem Biophys Res Commun 1999;254:264-268. 
29. Carrell RW, Lomas DA. Conformational disease. Lancet 1997;350: 134-138.

30. Hernandez-Espinosa D, Ayala I, Castells MT, et al. Intracellular retention of hepatic serpins caused by severe hyperlipidemia. Liver Int 2006;26:708-715.

31. Hernández-Espinosa $D$, Mota $R$, Miñano $A$, et al. In vivo effects of hyperthermia on the functional and conformational characteristics of antithrombin. J Thromb Haemost 2007;5:963-970.

32. Lomas DA, Parfrey H. $\alpha 1$-antitrypsin deficiency 4: molecular pathophysiology. Thorax 2004;59:529-535.

33. Kaufman RJ. Stress signaling from the lumen of the endoplasmic reticulum: coordination of gene transcriptional and translational controls. Genes Dev 1999;13:1211-1213.

34. Johnston JA, Ward CL, Kopito RR. Aggresomes: a cellular response to misfolded proteins. J Cell Biol 1998;143:1883-1898.

35. French BA, van Leeuwen F, Riley NE et al. Aggresome formation in liver cells in response to different toxic mechanisms: role of the ubiquitinproteasome pathway and the frameshift mutant of ubiquitin. Exp Mol Pathol 2001;71:241-246.

36. Bardag-Gorce F, Riley NE, Nan L, et al. The proteasome inhibitor, PS-341, causes cytokeratin aggresome formation. Exp Mol Pathol 2004;76:9-16.

37. Moura Nunes JF, Soares J, Costa MC. Confronting cisternae in human hepatocellular carcinoma. J Submicrosc Cytol 1986;18:441-444.

38. Witzleben CL, Marshall GS, Wenner W, et al. HIV as a cause of giant cell hepatitis. Hum Pathol 1988;19:603-605.

39. Palisano JR. The origin and role of confronting cisternae in selected fetal mouse and rat tissues. Cell Biol Int Rep 1990;14:1025-1032.

40. Watanabe $\mathrm{S}$, Ito $\mathrm{T}$, Shirai $\mathrm{M}$, et al. Electron microscopic studies of peripheral blood mononuclear cells in chronic type $C$ hepatitis treated with interferon-alpha. Ultrastruct Pathol 1995;19:1-8.

41. Stumptner C, Fuchsbichler A, Heid H, et al. Mallory body-a diseaseassociated type of sequestosome. Hepatology 2002;35:1053-1062.
42. Mathew A, Mathur SK, Morimoto RI. Heat shock response and protein degradation: regulation of HSF2 by the ubiquitin-proteasome pathway. Mol Cell Biol 1998;18:5091-5098.

43. Bruce D, Perry DJ, Borg JY, et al. Thromboembolic disease due to thermolabile conformational changes of antithrombin Rouen-VI (187 Asn $\rightarrow$ Asp). J Clin Invest 1994;94:2265-2274.

44. Picard V, Dautzenberg MD, Villoutreix BO, et al. Antithrombin Phe229Leu: a new homozygous variant leading to spontaneous antithrombin polymerization in vivo associated with severe childhood thrombosis. Blood 2003;102:919-925.

45. Beauchamp NJ, Pike RN, Daly $M$, et al. Antithrombins Wibble and Wobble (T85M/K): archetypal conformational diseases with in vivo latent-transition, thrombosis, and heparin activation. Blood 1998;92:2696-2706.

46. Corral J, Rivera J, Guerrero JA, et al. Latent and polymeric antithrombin: clearance and potential thrombotic risk. Exp Biol Med 2007;232:219-226.

47. Roemisch J, Gray E, Hoffmann JN, Wiedermann CJ. Antithrombin: a new look at the actions of a serine protease inhibitor. Blood Coagul Fibrinolysis 2002;13:657-670.

48. Davis NB, Taber DA, Ansari RH, et al. Phase II trial of PS-341 in patients with renal cell cancer: a University of Chicago phase II consortium study. J Clin Oncol 2004;22:115-119.

49. Rosinol L, Montoto S, Cibeira MT, et al. Bortezomib-induced severe hepatitis in multiple myeloma: a case report. Arch Intern Med 2005;165:464-465.

50. Miyakoshi S, Kami M, Yuji K, et al. Severe pulmonary complications in Japanese patients after bortezomib treatment for refractory multiple myeloma. Blood 2006;107:3492-3494.

51. Zappasodi P, Dore R, Castagnola C, et al. Rapid response to high-dose steroids of severe bortezomib-related pulmonary complication in multiple myeloma. J Clin Oncol 2007;25:3380-3381.

52. Harousseau JL. Thalidomide in multiple myeloma: past, present and future. Future Oncol 2006;2:577-589. 